\title{
Evaluation of the Solar Quiet Reference Field (SQRF) model for space weather applications in the South America Magnetic Anomaly
}

\author{
Sony Su Chen ${ }^{1 *}$ (i), Clezio Marcos Denardini ${ }^{1}$, Láysa Cristina Araujo Resende ${ }^{1,2}$, Ronan Arraes Jardim Chagas $^{1}$,
} Juliano Moro ${ }^{2,3}$, Régia Pereira da Silva ${ }^{1}$, Carolina de Sousa do Carmo ${ }^{1}$ and Giorgio Arlan da Silva Picanço ${ }^{1}$

\begin{abstract}
In the present work, we evaluate the accuracy of the Solar Quiet Reference Field (SQRF) model for estimating and predicting the geomagnetic solar quiet (Sq) daily field variation in the South America Magnetic Anomaly (SAMA) region. This model is based on the data set of fluxgate magnetometers from 12 magnetic stations of the Embrace Magnetometer Network (Embrace MagNet) from 2010 to 2018. The model predicts the monthly average horizontal field of the geomagnetic quiet (Sq-H) daily variation solving a set of equations for the specified geographic coordinates in terms of the solar cycle activity, the day of the year, and the universal time. We carried out two comparisons between the prediction and observational data of the Sq-H field. The first part attempts to evaluate the accuracy for estimating the Sq-H field over Medianeira (MED, $25.30^{\circ} \mathrm{S}, 54.11^{\circ} \mathrm{W}$, dip angle: $-33.45^{\circ}$ ) by using linear interpolation on the SQRF coefficients and comparing it with the data collected from April to December in 2018. None of the datasets collected at MED is part of the dataset used to build the SQRF model. The second part of the analysis attempts to evaluate the accuracy for predicting the quiet daily field variation over Cachoeira Paulista $\left(\mathrm{CXP}, 22.70^{\circ} \mathrm{S}, 45.01^{\circ} \mathrm{W}\right.$, dip angle: $-38.48^{\circ}$ ). The dataset collected at CXP before the period analyzed in the present work is part of the dataset used to build the SQRF model. Thus, the prediction accuracy is tested using magnetic data outside the time interval considered in the model. The prediction results for both locations show that this empirical model's outputs present a good agreement with the Sq-H field obtained from the ground-based magnetometer measurements. The accuracy of the SQRF model (high correlation, $r>0.9$ ) indicates a high potential for estimating and predicting geomagnetic quiet daily field variation. Concerning space weather applications, the model improves the scientific insight and capability of space weather prediction centers to predict the variability of the regular solar quiet field variation as reference conditions, which may include areas with no measurements.
\end{abstract}

Keywords: Geomagnetic quiet daily field variation, Space weather, Predicting, Empirical model

\section{Introduction}

Over the past centuries, the International Polar Years (IPY, 1882-1883 and 1932-1933) and the International Geophysical Year (IGY, 1957-1958) encouraged the studies and monitoring of the Earth's magnetic field (Jankowski and Sucksdorff 1996). More recently, the

\footnotetext{
*Correspondence: sony.chen@inpe.br

${ }^{1}$ National Institute for Space Research (INPE), São José dos Campos, SP, Brazil

Full list of author information is available at the end of the article
}

International Heliophysical Year (IHY, 2007-2008) aimed to fulfill fundamental global questions of Earth and space sciences (Davila et al. 2004). These conferences promoted a significant increase in the number of continuous and high-resolution ground-based observations of the geomagnetic field to understand the Earth's magnetism and space weather conditions (Yumoto et al. 1996; Love 2008; Thompson 2014; Love and Finn 2017).

The increase in ground-based instrumentation is associated with the creation of several regional warning 
and prediction centers of the Solar-Terrestrial environment (Schrijver et al. 2015; Denardini et al. 2016). In this context, the Brazilian Study and Monitoring of Space Weather (Embrace) Program lead by the National Institute for Space Research (INPE) joined in part of international collaborations, made an effort to fulfill the gaps of continuous temporal and spatial ground-based magnetometer data in South America (Denardini et al. 2016, 2018a). Some ionospheric indices for the space weather applications using ground-based instrumentation and satellite data developed on the Embrace Program can be found in Resende et al. (2019) and Denardini et al. (2020). Also, several authors used magnetic field measurements to estimate the magnitude of disturbed and storm-time periods driven by solar events (e.g., Klausner et al. 2016; Bolzan et al. 2018; Denardini et al. 2018b). Other studies estimated the magnitude of geomagnetic induced currents (GICs) from those ground-based observations (e.g., Espinosa et al. 2019; Rodger et al. 2020).

A large number of ground-based instrumentation and satellite data are essential to detail the geomagnetic field with a high cadence in time and spatial resolution. The ground-based observations are used to estimate the effects of the Earth's system changes, which may cause damages to technological assets. In the South America Magnetic Anomaly (SAMA) region, magnetometer data from Embrace Magnetometer Network (Embrace MagNet) show that it is important to have a specific index to quantify the geomagnetic field behavior (Denardini et al. 2015).

The SAMA is continuously monitored due to its higher radiation levels that may affect orbiting objects that pass across its region. It is well-known through the past decades that the SAMA region has three main characteristics: (1) its area is increasing, (2) the total field intensity is decreasing, and (3) there is a westward movement of its center (Pinto Jr. et al. 1992; Hartmann and Pacca 2009; Anderson et al. 2018). Recently, Finlay et al. (2020) observed that the SAMA continues to expand, and single-event electronic upsets recorded onboard the Swarm satellites seen directly related to the magnetic measurements in this region. Therefore, it is fundamental to monitor and study the anomalously weak geomagnetic field to understand how this anomaly can affect the physical parameters and dynamics in terms of space weather besides the technological equipment.

The development of empirical models has always played an essential role in this context. They are mostly used to estimate and predict the space weather during disturbed conditions (e.g., solar flares, coronal mass ejections, solar and galactic energetic particles, and solar wind variations). These models are developed to benefit human activities affected by the near-Earth space environment (Bala and Reiff 2018, and references therein). The empirical models of geomagnetic field variations are commonly used to estimate quiet time conditions, e.g., the main field and its secular variation (Thébault et al. 2015; Chulliat et al. 2020). Mandea and Chambodut (2020) have presented some concerns about the range of spatial and temporal variabilities of the geomagnetic field and their space weather implications. These authors affirmed that continuous global observations of internal and external geomagnetic field sources are needed to improve space weather prediction.

The geomagnetic quiet field variation has been extensively reviewed and described by Richmond (1979), Campbell (1989), and Yamazaki and Maute (2017). This horizontal field daily variation, or Sq field, is related to the solar thermal wind tides generated in the thermosphere and the ionospheric conductivities. There are models developed for the South African (Sutcliffe 1999), Asian and Oceania (Yamazaki et al. 2011), and Indian sectors (Unnikrishnan 2014). Besides, other models were developed for high latitude regions, such as those presented by Janzhura and Troshichev (2008) and Stauning (2011). A global-scale empirical model of the geomagnetically quiet daily variation was developed by Campbell et al. (1989). However, this model has not been updated. Soares et al. (2020) described the Sq field at the Brazilian station Tatuoca $\left(1.2^{\circ} \mathrm{S}, 48.5^{\circ} \mathrm{W}\right)$ and its long-term changes associated with the secular variation. But, Tatuoca is a few thousand kilometers away from the SAMA, and the behavior of the Sq field in the SAMA region is still to be understood. Recently, satellite and groundbased magnetic field measurements were used to developed global-scale Sq field models by Sabaka et al. (2020) and Chulliat et al. (2016). These recent works provided much greater spatial coverage of the Sq field worldwide using satellite magnetic field measurements compared to the ground-based magnetic field measurements. Nevertheless, there is still low spatial coverage of ground-based magnetic field measurements around the SAMA region.

In the present study, we attempt to develop an estimating and predicting tool for obtaining the solar quiet daily variation of the geomagnetic field at the SAMA. The analysis is based on the empirical model developed by Chen et al. (2020). This predicting tool estimates the $\mathrm{Sq}-\mathrm{H}$ field for a region based on a linear interpolation method on the SQRF parameters of two magnetic stations, both close to the same meridian. The predicting tool estimates the daily variation for a given location with high accuracy within 1 to 3 months. The evaluation shows high accuracy for estimating and predicting the geomagnetic quiet daily field variation, with a good agreement to the magnetic field data. 


\section{The empirical model for the Sq-H field and input parameters}

We used the Solar Quiet Reference Field (SQRF) model to estimate and predict the $\mathrm{Sq}-\mathrm{H}$ field in the SAMA region (Chen et al. 2020), an empirical model based on the daily variation of the horizontal field obtained by magnetic field data collected from Embrace MagNet (Denardini et al. 2018a). Such a model reveals the climatology of geomagnetic quiet daily variation across South America. This model expresses the combination of primary (external) and secondary (induced) Sq fields, which is sufficient for the purpose of this work.

In short, the SQRF model was obtained by fitting a function that depends on solar radio flux $\left(F_{10.7}\right)$, day of the year (DOY), and universal time (UT). The model was built using magnetic field data collected from 12 stations across the Brazilian sector from 2010 to 2018, as seen in Table 1. A map with the location of such Embrace MagNet stations is shown in Fig. 1. In this figure, the red stars indicate the magnetic stations and circles indicate the SAMA region center, where the minimum field intensity was 22,567 nT in 2010 and evolved to 22,287 nT in 2018. Solid lines indicate the SAMA region where the total intensity is lower than 23,000 nT. Dashed lines correspond to the magnetic equator. The orange and green colors indicate the year 2010 and 2018, respectively. The total field intensity, the magnetic equator, and quasidipole geomagnetic coordinates were obtained using the IGRF-13.

The SQRF model is based on the monthly average of the quiet daily variation of the geomagnetic field horizontal component measured by fluxgate magnetometers. This quiet daily field variation is an average of the

Table 1 Embrace MagNet stations from which the data were obtained to build the SQRF model

\begin{tabular}{|c|c|c|c|c|c|}
\hline \multicolumn{2}{|c|}{ Station } & \multicolumn{2}{|c|}{ Geog. coord } & \multicolumn{2}{|c|}{$\begin{array}{l}\text { Geom. quasi- } \\
\text { dipole }\end{array}$} \\
\hline Code & Name & Lat. $\left({ }^{\circ} \mathrm{N}\right)$ & Lon. $\left({ }^{\circ} \mathrm{E}\right)$ & Lat. $\left({ }^{\circ} \mathrm{N}\right)$ & Lon. $\left({ }^{\circ} \mathrm{E}\right)$ \\
\hline MAN & Manaus & -2.89 & -59.97 & 4.23 & 13.40 \\
\hline ALF & Alta Floresta & -9.87 & -56.10 & -3.74 & 15.17 \\
\hline SLZ & São Luís & -2.59 & -44.21 & -3.82 & 27.73 \\
\hline ARA & Araguatins & -5.60 & -48.10 & -4.26 & 23.34 \\
\hline EUS & Eusébio & -3.88 & -38.42 & -8.02 & 32.55 \\
\hline CBA & Cuiabá & -15.55 & -56.07 & -8.68 & 13.87 \\
\hline JAT & Jataí & -17.93 & -51.72 & -12.69 & 16.92 \\
\hline TCM & Tucumán & -26.82 & -65.19 & -15.67 & 5.10 \\
\hline SJC & São José dos Campos & -23.21 & -45.96 & -19.65 & 20.50 \\
\hline CXP & Cachoeira Paulista & -22.70 & -45.01 & -19.71 & 21.39 \\
\hline VSS & Vassouras & -22.40 & -43.65 & -20.13 & 22.59 \\
\hline SMS & São Martinho da Serra & -29.44 & -53.82 & -21.32 & 13.36 \\
\hline
\end{tabular}

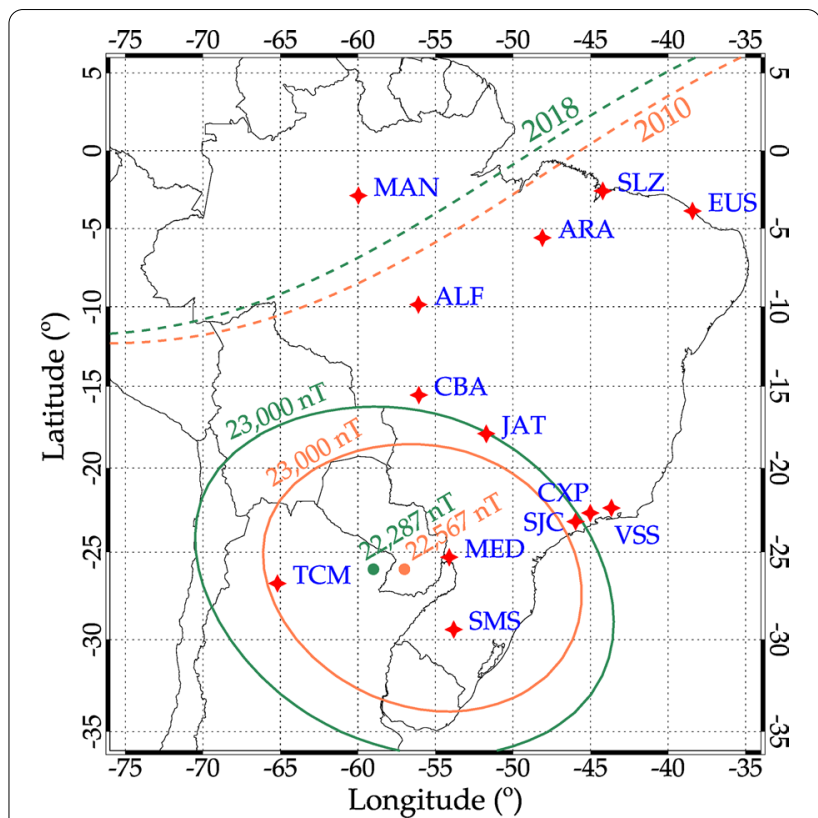

Fig. 1 Map of geographic coordinates of the Embrace MagNet stations (stars) in the Brazilian sector, along with solid lines indicating the SAMA region $(23,000 \mathrm{nT})$ and the magnetic equator. The total field intensity and the magnetic equator were obtained using the IGRF-13 for epochs 2018.0 (green) and 2010.0 (orange)

magnetic field measured during the 5 quietest days of the month, based on the list of International Quiet Days (IQDs) from GeoForschungsZentrum (GFZ) Potsdam. The derived daily variation of observational data is given by:

$$
\begin{aligned}
& H_{\mathrm{QDC}}(\mathrm{UT})=\frac{1}{N} \sum_{i=1}^{5} H_{\mathrm{Qd}_{i}}(\mathrm{UT}) \\
& \Delta H_{\mathrm{QDC}}(\mathrm{UT})=H_{\mathrm{QDC}}(\mathrm{UT})-H_{\mathrm{QDC}}(00: 00 \mathrm{LT}),
\end{aligned}
$$

where $H_{\mathrm{QDC}}$ is the $\mathrm{Sq}-\mathrm{H}$ field, $H_{\mathrm{Qd} i}$ is the daily variation of the $i$ th quietest day of the month, $U T$ is the universal time given with 1-min time resolution (from 00:00 up to 23:59 UT), and $N$ is the number of days used in the calculation. Eventually, the number of days used for the $H_{\mathrm{QDC}}$ computation can be less than 5 , depending on the data availability. $\Delta H_{\mathrm{QDC}}$ is the Sq-H field amplitude obtained from the magnetic data by subtracting the baseline. $H_{\mathrm{QDC}}$ (00:00 LT) is the baseline and corresponds to the daily variation during local midnight.

The Sq-H field model development consists of parametrization of solar cycle dependence, seasonal variation, and daily variation on the observational data of $\Delta H_{\mathrm{QDC}}$. These three parameters are computed separately for each magnetic station. The solar cycle 
parameter describes the linear relationship between the monthly average of the $\Delta H_{\mathrm{ODC}}$ during local noon (12 LT) and the monthly average solar radio flux, $F_{10.7}$ (1 $\mathrm{sfu}=10^{-22} \mathrm{~W} \mathrm{~m}^{-2} \mathrm{~Hz}^{-1}$ ), given by Eq. (3). The seasonal parameter describes the time-series' parametrization for the monthly average of the $\Delta H_{\mathrm{QDC}}$ during local noon over the days of the year, given by Eq. (4). Lastly, the daily parameter describes the time-series for the monthly average of the $\Delta H_{\mathrm{QDC}}$ during the $24 \mathrm{~h}$ of the day, caused by 24-, 12-, 8-, and 6-h harmonics of the day, given by Eq. (5). Thus, these parameters are modeled by the following set of equations:

$$
\begin{aligned}
& C\left(F_{10.7}\right)=C_{0}+C_{1} F_{10.7} \\
& S(\mathrm{DOY})=S_{0}+\sum_{j=1}^{N} S_{j} \cos \left(2 \pi j \mathrm{DOY}+\phi_{j}\right) \\
& D_{m}(\mathrm{UT})=D_{m, 0}+\sum_{n=1}^{N} D_{m, n} \cos \left(2 \pi f_{n} \mathrm{UT}+\phi_{m, n}\right),
\end{aligned}
$$

where $C$ is the solar cycle parameter given in $\mathrm{nT}, C_{0}$ and $C_{1}$ are the linear regression coefficients between the $\Delta H_{Q D C}(12 \mathrm{LT})$ and the solar radio flux monthly average, $F_{10.7} . S$ is the seasonality parameter, in which $S_{0}$ up to $S_{N}$ (being $N=6$ ) are coefficients obtained from the Fourier series fitting, $j$ is the number of the $j$ th harmonic, $\phi_{j}$ is the phase angle of the $j$ th harmonic, and DOY is the day of the year. $D_{m}$ is the daily variation parameter referred to the selected month $m$ (i.e., $m=1$ for January, $m=2$ for February, $m=3$ for March, ..., $m=12$ for December, and corresponds to the central date of each month; $D O Y=15$, $46,74, \ldots, 349$ ), where $D_{0}$ up to $D_{N}$ are the fitted coefficients, $f_{n}$ is the frequency of the $n$th harmonic, $\phi_{n}$ is the phase angle of the $n$th harmonic (being $N=4$ ). Notice that $S$ and $D_{m}$ are dimensionless parameters that account for the seasonality and daily variation, respectively.

Considering the three mentioned modeled parameters in equations above $\left(C, S\right.$, and $\left.D_{m}\right)$, the $\mathrm{Sq}-\mathrm{H}$ field is given by:

$$
\Delta H_{\mathrm{QDC}}^{*}\left(F_{10.7}, \mathrm{DOY}, \mathrm{UT}\right)=C\left(F_{10.7}\right) \cdot S(\mathrm{DOY}) \cdot D_{m}(\mathrm{UT}) .
$$

$S$ (DOY) uses the day of the year to model the $\Delta H_{\mathrm{QDC}}^{*}$ seasonal variation. On the other hand, $D_{m}(\mathrm{UT})$ encompasses the changes over time within a day. The latter is obtained for each month $m$ separately as this improved the model performance. We normalized the seasonal and daily parameters to get their relative geomagnetic field variations. $\Delta H_{Q D C}^{*}$ is the Sq-H field amplitude obtained from the SQRF model. Details about the coefficients, as well as the description of all fitting equations of parameters above, are given in Chen et al. (2020).

The SQRF model is based on Yamazaki et al. (2011), in which the geomagnetic field daily variation is calculated through the least-square fitting of multivariable functions to observational data. However, the SQRF model does not consider the lunar tide on the geomagnetic field daily variation since the model only provides a monthly $\mathrm{Sq}$ variation based on each month's five quietest days. Additionally, Yamazaki et al. (2011) developed a model for the $210^{\circ}$ magnetic meridian, which has none of the SAMA region characteristics mentioned above. Thus, the SQRF model may successfully describe the SAMA region dynamics since it is based on ground-based magnetic field measurements in this region.

Thus, we present two analyses to evaluate the SQRF model accuracy in estimating and predicting the $\mathrm{Sq}-\mathrm{H}$ field in the SAMA region. The first one is about an interpolation method used to estimate the $\mathrm{Sq}-\mathrm{H}$ field over MED, a region close to the SAMA center. The other is about predicting the Sq-H field for CXP, considering the empirical model coefficients obtained from the magnetic field data from 2010 to 2018 . The observational data used to compare with the empirical model are derived from Eqs. (1) and (2).

\section{Results and discussion Estimating the Sq-H field}

We present here a spatial interpolation method to improve the SQRF model, which allows the user to estimate the $\mathrm{Sq}-\mathrm{H}$ field over a region where magnetic data are not available. This method uses linear interpolation on the empirical model's parameters based on the magnetic stations' geographic latitude. We show in the following an example of this interpolation to illustrate the method. Initially, we selected a substantial amount of magnetic field data collected by two magnetic stations from the Embrace MagNet from 2010 to 2018. Afterward, we estimate the Sq-H field for a site between those magnetic stations.

In this example, the SQRF computed the values for Cuiabá $\left(\mathrm{CBA}, 15.55^{\circ} \mathrm{S}, 56.07^{\circ} \mathrm{W}\right.$, dip angle: $\left.-18.58^{\circ}\right)$ and São Martinho da Serra (SMS, $29.44^{\circ} \mathrm{S}, 53.82^{\circ} \mathrm{W}$, dip angle: $\left.-37.69^{\circ}\right)$ to obtain the modeled results for Medianeira (MED, $25.30^{\circ} \mathrm{S}, 54.11^{\circ} \mathrm{W}$, dip angle: $-33.45^{\circ}$ ), a region close to the SAMA center. Embrace MagNet installed a magnetometer in Medianeira at the beginning of April 2018. Thus, none of the datasets collected at MED was considered to obtain the SQRF model parameters. Instead, the parameters for MED were obtained from interpolation between parameters from other magnetic stations. Therefore, we were able to compare the 
estimated $\mathrm{Sq}-\mathrm{H}$ field for the MED station and the magnetic data collected over it for 2018. Additionally, these three sites are located almost at the same meridian.

Figure 2 shows the parameters used as the model input for MED (red), based on CBA (blue) and SMS (green) stations. The fitted parameters were based on (a) the solar cycle dependence; (b) the seasonal variation, and (c) the daily variation. Notice that the daily variation in Fig. 2c corresponds to December $(m=12)$. However, $D_{m}$ was obtained for all 12 months, individually (i.e., from $m=1$ up to $m=12$ ).

The solar cycle dependence ( $C$ parameter) is represented by a linear relationship between the Sq amplitudes at $12 \mathrm{LT}(\mathrm{LT}=\mathrm{UT}-3)$ and the $F_{10.7}$ index (Fig. $\left.2 \mathrm{a}\right)$. This behavior agrees with previous works such as Rastogi et al. (1994) and Shinbori et al. (2017) over the Indian and Asian sectors, respectively. This parameter is essential in the model since the $F_{10.7}$ index estimates the solar cycle dependence in the heights of our interest.

Figure $2 \mathrm{~b}$ shows that the $\mathrm{Sq}-\mathrm{H}$ field at local noon (12 LT) has a cyclic component during the year, which is the seasonal variation $(S)$. This parameter agreed with the tidal behavior of the atmospheric oscillations described by Forbes et al. (2008). The results show that the highest amplitude values were observed during March (DOY 75 ) and September equinoxes (DOY 255). In contrast, the lowest amplitude values were seen during the winter solstice period (between DOY 135 and 195) in the Southern Hemisphere.

Kane (1976) shows that the Sq field at local noon has a semiannual variation with maximum values at the equinoxes. Recently, Yamazaki et al. (2014) showed that the region close to the magnetic equator has a well-defined semiannual variation due to the high conductivity. At low latitudes, which is the focus of this study, previous works have shown that these phenomena are more expressive in the equinoxes. It is well-known that the tidal winds in the ionospheric E-region play an important role in the ionospheric dynamo (Campbell 1989), contributing to the seasonal variation in the analyzed heights of this region. Batista et al. (2004) showed that the diurnal and semidiurnal tides have a well-defined variability characterized by maximum amplitudes at the equinoxes over the Brazilian sector. Resende et al. (2017) analyzed the influence of the tidal components in the denser layer formation in the ionospheric E-region, widely known as sporadic (Es) layers, at low-latitude regions. The authors showed that these layers occurred with more intensity during the equinoxes since the tidal winds are stronger in these periods. Therefore, there is a good agreement of the seasonal behavior obtained using the magnetometer data with the previous studies, corroborating the model effectiveness.

The daily parameter, or $D_{m}$ in the SQRF model, refers to the daytime variation considering atmospheric tides' harmonics. $D_{m}$ determines the daily variation amplitude of the geomagnetic field horizontal component concerning the diurnal, semidiurnal, terdiurnal, and quarterdiurnal tides (whose periods are 24-, 12-, 8-, and 6-h, respectively). Figure 2c shows the $\mathrm{Sq}-\mathrm{H}$ amplitude considering those oscillations for December $(m=12)$.

The horizontal field daily variation has a characteristic behavior related to the ionospheric conductivities (Moro et al. 2016). During the summer solstice, in geomagnetically quiet periods, the solar incidence is higher, increasing the ionospheric conductivity in the E-region (Van de Kamp 2013). Thus, the Sq field varies proportional to the conductivity and the ionospheric electric field, with the amplitude in CBA reaching almost $60 \mathrm{nT}$ in December. Additionally, the CBA station is characterized by higher values than those observed in SMS. It occurs because the
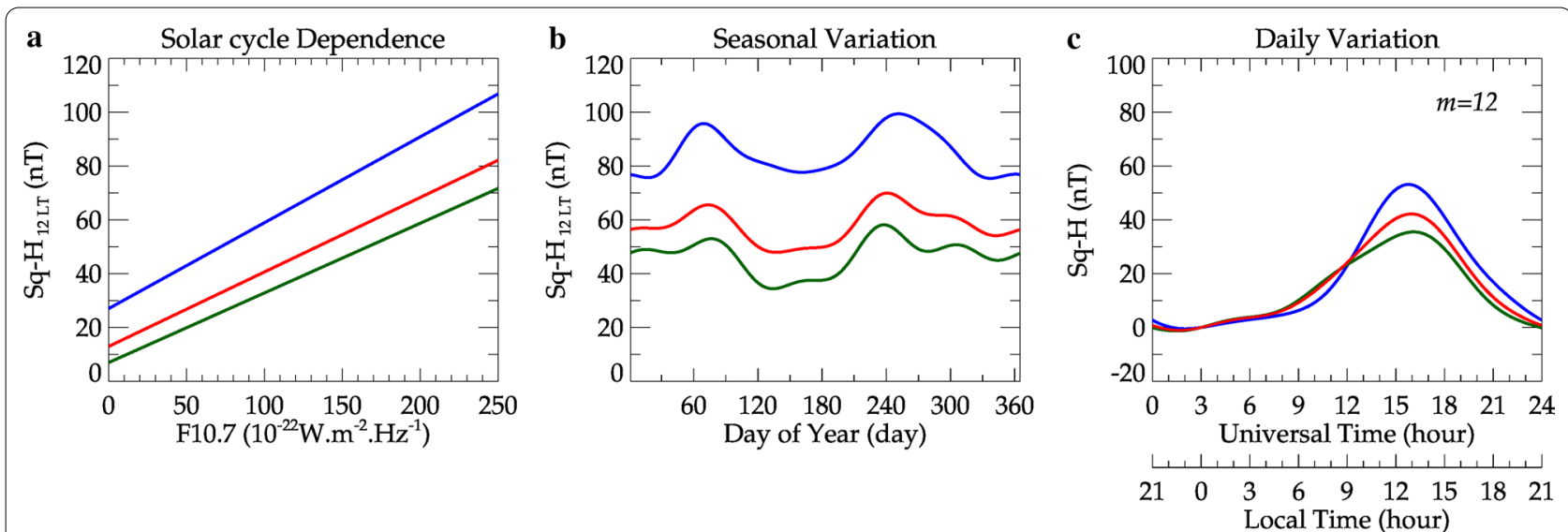

Fig. 2 Interpolated parameters obtained for MED (red), based on CBA (blue) and SMS (green) parameters. a Solar cycle parameter. b Seasonal variation parameter. c Daily variation parameter for December $(m=12)$ 
former station is closer to the magnetic dip equator than the second. Thus, the Sq current system configuration makes the horizontal currents stronger. The interpolated parameters over MED have intermediate values between CBA and SMS.

The coefficients for each parameter of the SQRF model from CBA and SMS stations are presented in the Appendix. A grid of values from these two stations' parameters is estimated according to its geographic latitude and being used linear interpolation for MED. Thus, we evaluated the interpolation method applied to $C, S$, and $D_{m}$ parameters in the SQRF model and checked if it was adequate to study regions with a low quantity of data such as MED. The empirical model results were compared with the magnetic field data collected by the MED station, as shown in Fig. 3. The Sq field variation estimated from the magnetic field data is obtained by the average of the 5 quietest days of the month, using Eqs. (1) and (2). We presented September $(m=9)$, November $(m=11)$, and December $(m=12)$ of 2018 as an example of this comparison (top panels in Fig. 3). Hereafter, we compared the estimated and the magnetic field data based on the linear fitting correlation of the monthly quiet daily field variation (bottom panels in Fig. 3).

We noticed that the Sq-H field estimation is very similar to the observational data (shape of the curve), with few discrepancies depending on the month analyzed. In September, we observed overestimated values during pre-dusk hours (18-21 UT) and underestimated values during post-dusk hours (21-24 UT). In November and December, the overestimate values occurred mostly between 18 and 24 UT. Despite this, the SQRF model estimates almost the same behavior observed in MED. The best correlation was observed in November 2018 $(r=0.99)$.

Table 2 summarizes the results for the above analysis extended for the whole period of 2018. The averaged Pearson correlation coefficient $r$ between the

\section{Table 2 Linear fit coefficients and correlation between the estimated daily field variation and the magnetic field data}

\begin{tabular}{llrlll}
\hline Year & Month & $\boldsymbol{a}(\mathbf{n T})$ & $\boldsymbol{b}$ & $\boldsymbol{r}$ & RMSE (nT) \\
\hline 2018 & 4 & 1.41 & 0.82 & 0.959 & 3.83 \\
& 5 & -1.25 & 1.00 & 0.986 & 2.03 \\
6 & 0.99 & 1.12 & 0.976 & 2.94 \\
& 7 & 1.78 & 1.17 & 0.979 & 3.79 \\
8 & 3.97 & 1.19 & 0.940 & 7.10 \\
9 & 0.80 & 1.04 & 0.983 & 2.81 \\
& 11 & 1.82 & 0.91 & 0.990 & 2.23 \\
& 12 & 1.86 & 1.09 & 0.968 & 3.92 \\
& Average & 1.42 & 1.04 & 0.973 & 3.58
\end{tabular}

The spatial interpolation was performed to modeled parameters for MED in 2018
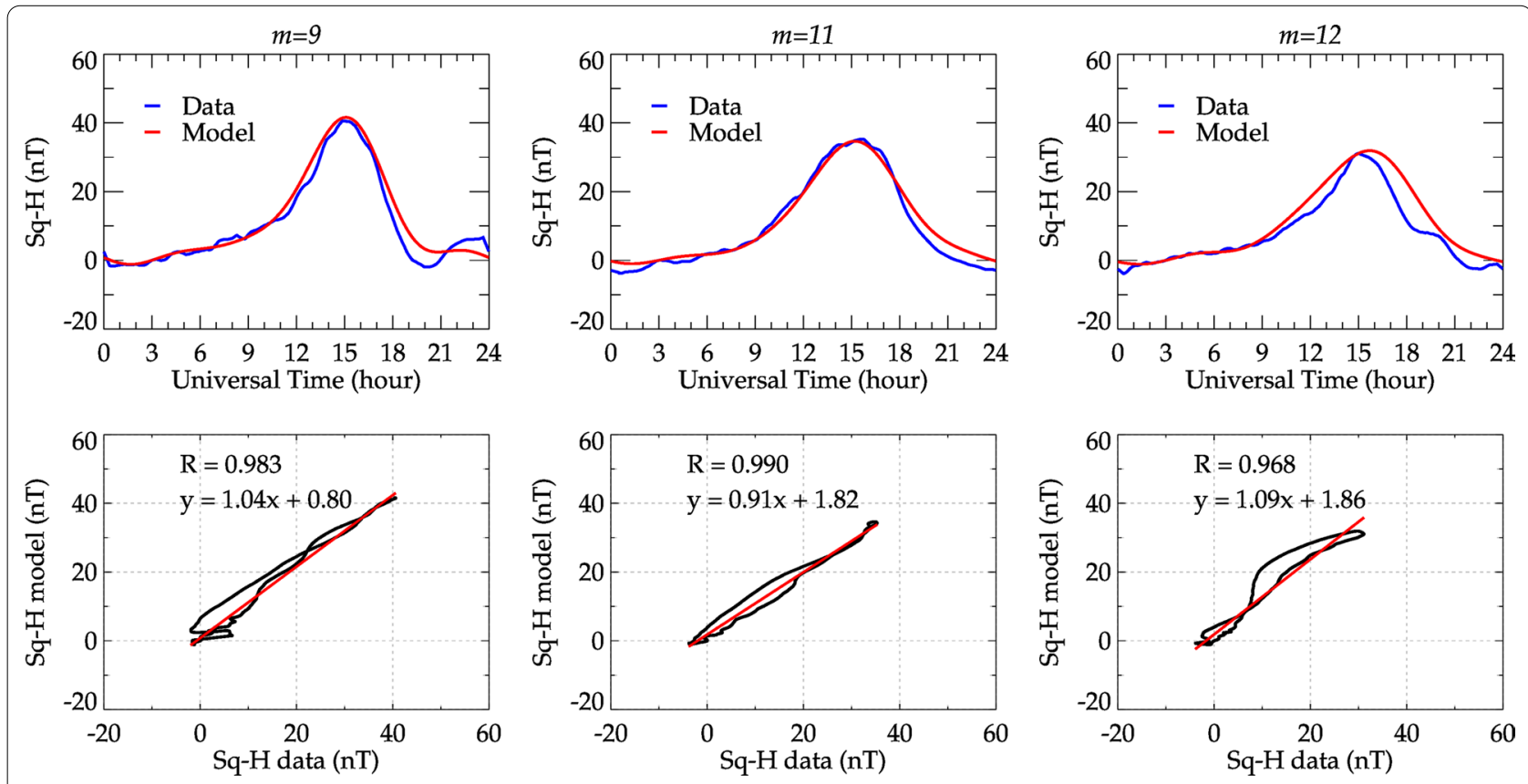

Fig. 3 Top panels correspond to the monthly Sq-H field obtained for MED using the interpolated parameters of the SQRF model (red) and the magnetic field data (blue) in September $(m=9)$, November $(m=11)$, and December $(m=12)$ in 2018. The bottom panels correspond to the dispersion plots of the $\mathrm{Sq}-\mathrm{H}$ field for each of the presented months 
observational data and the SQRF model for MED was higher than 0.97, indicating that the regression has a high confidence level. The linear regression obtained from this correlation shows that the modeled Sq-H field amplitude overestimated about $4 \%$ on average (coefficient $b$ ) the observational data, which means that the SQRF model provides an accurate estimation for the $\mathrm{Sq}-\mathrm{H}$ field. The $\mathrm{Sq}-\mathrm{H}$ field is also in good agreement with the magnetic field data collected over the magnetic station, with an offset of about $1.4 \mathrm{nT}$ in the linear coefficient $a$.

The root mean square error (RMSE) was calculated to evaluate the SQRF model accuracy. We attempted to verify the possibility of estimating the $\mathrm{Sq}-\mathrm{H}$ field behavior for regions with no available data. The averaged RMSE was about $3.6 \mathrm{nT}$, indicating an error of approximately $11.4 \%$ of the $\mathrm{Sq}-\mathrm{H}$ field if the amplitude during local noon is $31.5 \mathrm{nT}$. The results show that the SQRF model achieved an accurate estimation in 2018, being more precise in May (lowest RMSE). However, some discrepancies were noticed in the correlation between the estimated Sq-H field and its magnetic field data in the June solstice (June, July, and August). The angular coefficient $b$ observed in the June solstice indicates that the SQRF model is predominantly overestimating the $\mathrm{Sq}-\mathrm{H}$ field by about $16 \%$, given that the coefficient $a$ is small. This result suggests that the MED station may have almost the same amplitude observed in SMS during the June solstice. This similar magnitude during this period for MED and SMS can be associated with the SAMA since these stations are close to the anomaly center.

The highest RMSE was observed in August 2018. In this case, some of the quiet days listed may not be entirely associated with geomagnetically quiet periods, which means that a double check must be done to the geomagnetic field data in the SAMA to obtain the Sq-H field. Abdu and Batista (1977) reported enhanced ionization at E-layer heights under magnetically quiet conditions from ionosonde data in the SAMA, which can explain why the SQRF model underestimates the observational data on some occasions.

We estimated the Sq-H field behavior for all months for 9 years (from January 2010 to December 2018). Figure 4 shows the contour graphs of the $\mathrm{Sq}-\mathrm{H}$ field from the SQRF model for (a) CBA, (b) MED, and (c) SMS. The typical Sq-H field behavior in observational data is characterized by a peak on the $\mathrm{Sq}-\mathrm{H}$ field around the local noon (12 LT), which is cyclical for each year (Chen et al. 2020). We see that the daytime variations are related to seasonality and occur due to the similar solar incidence in the atmosphere over the magnetic stations.

In general, the Sq-H field in the MED station seems to be the average of the stations used for this analysis, as expected. Some discrepancies were noticed, but the behavior is well correlated with that expected in low latitudes. We observed that the contour graph of MED presents the $\mathrm{Sq}-\mathrm{H}$ field similar to that found in the SMS contour graph. However, the maximum value of the $\mathrm{Sq}-\mathrm{H}$ field in MED is higher than that observed in SMS. This difference is due to the CBA region influence, in which the Sq magnitude is more enhanced than that observed in SMS, as mentioned before. The interpolation method applied to the SQRF coefficients presents a very accurate estimation and can be used to estimate the $\mathrm{Sq}-\mathrm{H}$ field for previous periods. Therefore, these results indicate that the SQRF model can be used for regions without sufficient data. For the interpolation method to work, one needs sufficient data in adjacent regions.

\section{Predicting the Sq-H field}

In this analysis, the solar cycle, seasonal, and daily parameters of the SQRF model are used to predict the $\mathrm{Sq}-\mathrm{H}$ field beyond 2018. We have evaluated the accuracy of the model for predicting the Sq-H field over Cachoeira Paulista (CXP, $22.70^{\circ} \mathrm{S}, 45.01^{\circ} \mathrm{W}$, dip angle: $-38.48^{\circ}$ ), a station that has the most significant amount of data.

We selected 3 months in 2019 (January, February, and March) to evaluate the model performance. The Sq-H field was calculated based on Eqs. (1) and (2), using the magnetic field data collected during the five quietest days (IQDs) of each month, as shown in Table 3. GFZ Potsdam provides the list of International Quiet Days. Thus, it is possible to compare the Sq-H field observed for the months of 2019 with the predictions.

Figure 5 shows the Sq-H field graphs of the observational data (in blue) and the predicting field (in red) for CXP in 2019. The vertical and horizontal axes correspond to the daily variation amplitudes and the hours of the day (UT), respectively. We also present a linear correlation between the observational data and the modeled magnetic field. It is observed that there is a good agreement between the predicted Sq-H field and the observational data for the analyzed period. Nevertheless, during the daytime in March, the model overestimates the observational data from 9 to $17 \mathrm{UT}$, being more expressive around local noon. We were expecting higher values for the Sq-H field amplitude during the March equinox, similar to that observed in Fig. 2b. This difference may be associated with the atmospheric tidal winds since the solar radio flux remains almost constant from monthto-month with lower values during solar minimum. Thus, the ionospheric current system variability is more affected by the atmospheric tidal winds than the ionospheric conductivities and electron density (Batista et al. 2004). It was demonstrated by Yamazaki et al. (2016). Therefore, the previous data's modeled parameters are not susceptible to this variability, causing this difference. 

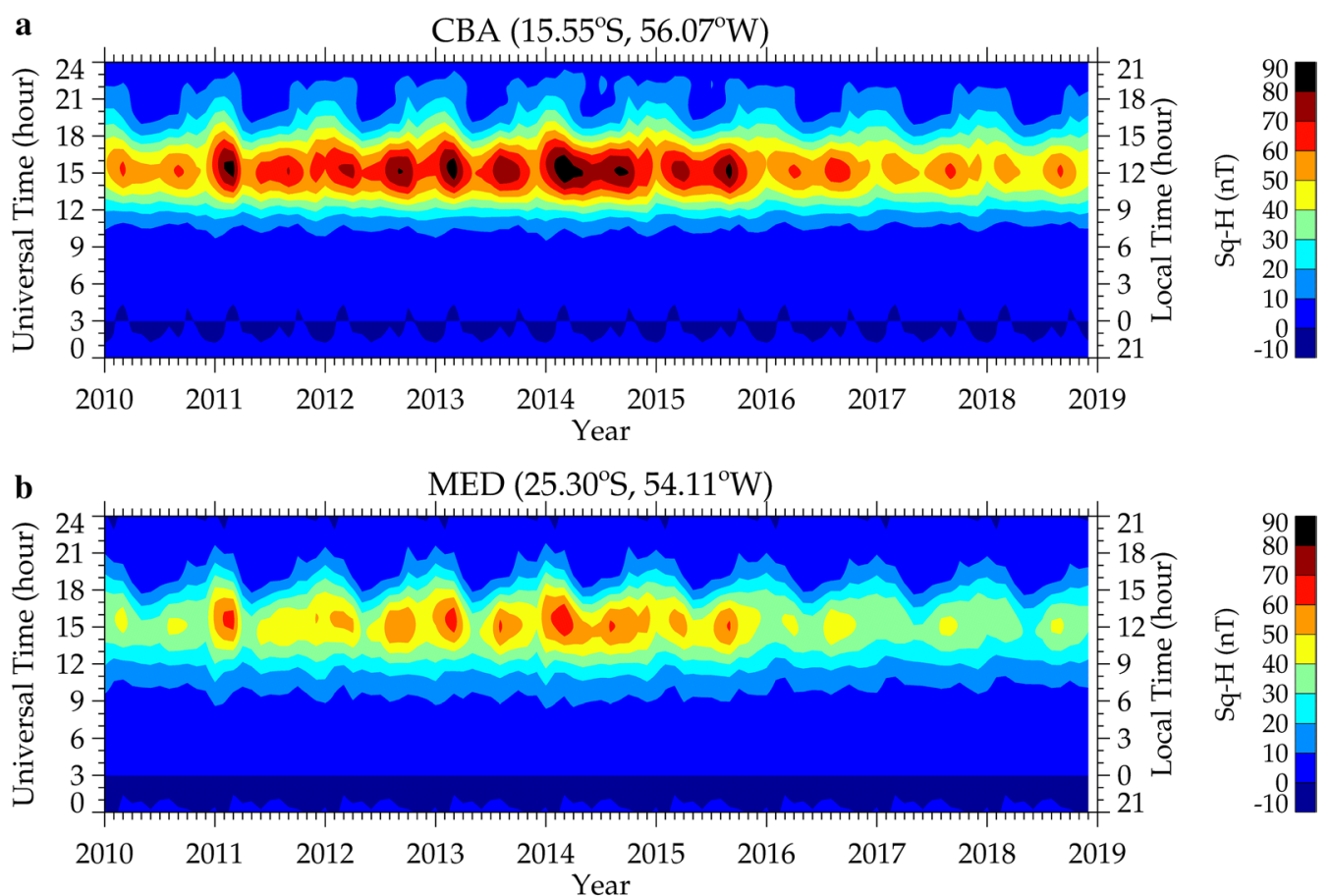

c

SMS $\left(29.44^{\circ} \mathrm{S}, 53.82^{\circ} \mathrm{W}\right)$
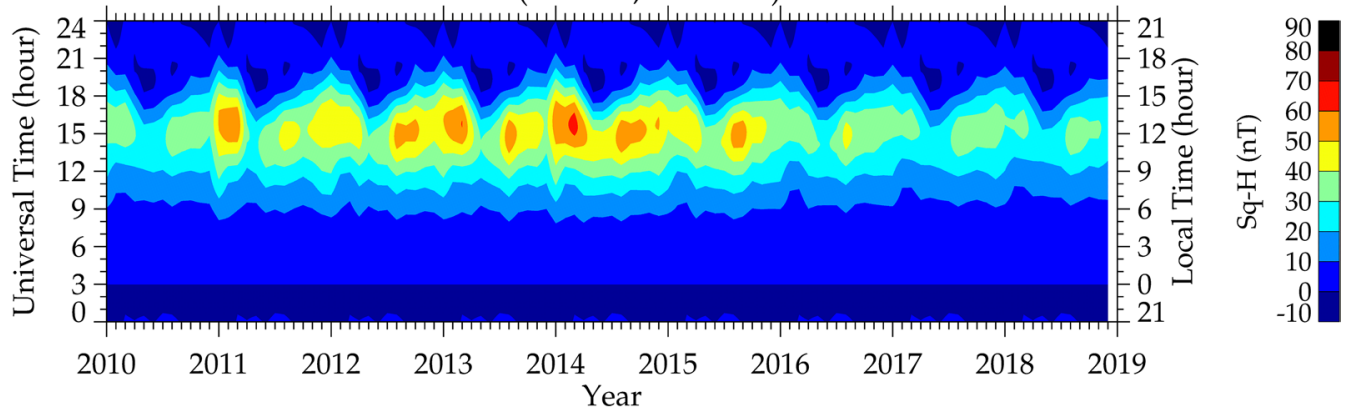

Fig. 4 Contour maps of the Sq-H field predictions for a CBA and c SMS, and estimations for b MED from January 2010 to December 2018

Table 3 List of five most quiet days from January to March in 2019

\begin{tabular}{lllllll}
\hline Year & Month & Quiet days & & & \\
\cline { 2 - 6 } & & Qd1 & Qd2 & Qd3 & Qd4 & Qd5 \\
\hline 2019 & 1 & 2 & 28 & 3 & 30 & 12 \\
& 2 & 25 & 24 & 23 & 19 & 18 \\
\hline
\end{tabular}

The results show that there is a challenge for predicting the Sq-H field more accurately when variabilities occur during quiet periods.

Table 4 shows the linear fitting coefficients $a$ and $b$ obtained from January to March in 2019, with the correlation coefficient $(r)$ and the RMSE. It can be seen that the Sq-H field obtained from the SQRF model has a very high correlation $(r>0.98)$ with the observational data. Also, the Sq-H field predictions overestimate the 

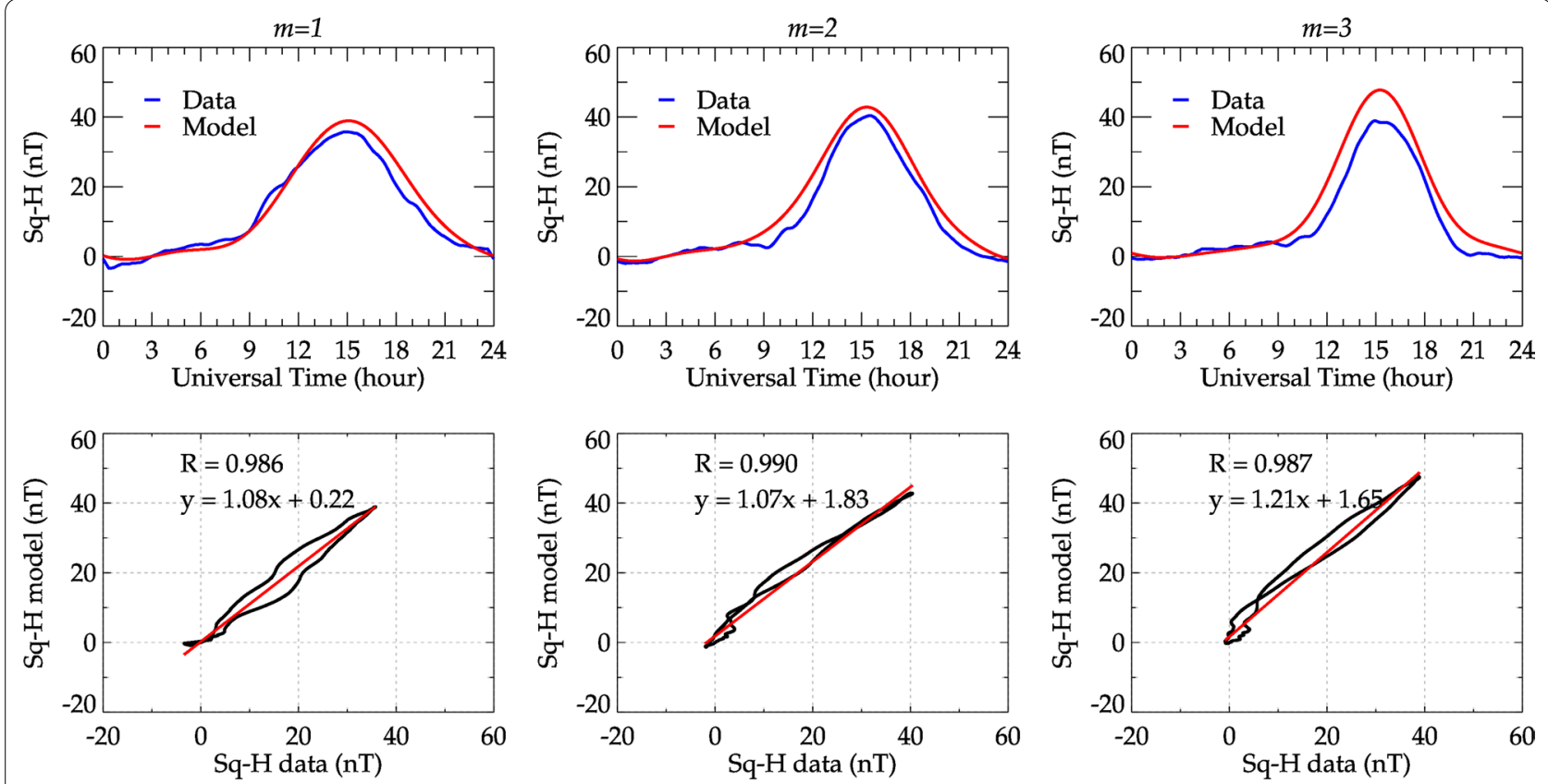

Fig. 5 Top panels correspond to the Sq-H field obtained for CXP using the magnetic field data (blue) and the SQRF model (red) for January to March 2019. The bottom panels correspond to the dispersion plots of the $\mathrm{Sq}-\mathrm{H}$ field for each of the presented months, respectively

\begin{tabular}{|c|c|c|c|c|c|}
\hline Year & Month & $a(\mathrm{nT})$ & $b$ & $r$ & RMSE (nT) \\
\hline \multirow[t]{4}{*}{2019} & 1 & 0.22 & 1.08 & 0.986 & 2.83 \\
\hline & 2 & 1.83 & 1.07 & 0.990 & 3.44 \\
\hline & 3 & 1.65 & 1.21 & 0.987 & 5.27 \\
\hline & Average & 1.23 & 1.12 & 0.988 & 3.85 \\
\hline
\end{tabular}

The predicting $\mathrm{Sq}-\mathrm{H}$ field was based on the modeled CXP station parameters based on the data from 2010 to 2018

magnitude of the quiet daily field variation, which is described by the linear fitting slope $(b)$, given that the coefficient $a$ is small. On average, the Sq-H field modeled here output values approximately $12 \%$ higher than that of the observational data for this magnetic station. However, this difference in the magnitude of the geomagnetic field quiet daily variation does not appear significant for space weather applications, given that the prediction errors were approximately $4 \mathrm{nT}$. For example, when deriving geomagnetic indices such as the Dst, this difference in magnitude in the Sq field may correspond to less than $1 \%$ for a severe magnetic storm (where the Dst index reaches - $400 \mathrm{nT}$ ). We have calculated the RMSE to evaluate the accuracy for predicting the $\mathrm{Sq}-\mathrm{H}$ field. In this case, the $\mathrm{Sq}-\mathrm{H}$ field predicted present averaged RMSE (3.8 nT) similar to that obtained in the previous analysis in "Estimating the Sq-H field" section. We noticed in Table 4 that the RMSE was relatively lower than the local noon amplitude, which indicates a low error when predicting the $\mathrm{Sq}-\mathrm{H}$ field. These results show that the SQRF model achieved an accurate prediction in all these months, being more precise in the first and second months (lowest RMSE). However, the SQRF model overestimated the Sq-H field from 9 to 24 UT in March 2019. Despite this, its Pearson correlation coefficient $(r=0.987)$ shows that the Sq-H field presents almost the same behavior as observational data.

Comparing these results, it is observed that the Sq-H field typical behavior was predicted with high accuracy. The daytime variations, including the noon peak on $\mathrm{Sq}$ amplitude, appear at the same time and magnitude. Also, the seasonality output by the model seems to match that of the observational data. Concerning the solar cycle dependence, the $F_{10.7}$ index was lower than usual during the solar minimum of solar cycle 24 . In that case, the $F_{10.7}$ index used as input for predicting the $\mathrm{Sq}-\mathrm{H}$ field had the 
same value for all 3 months. However, the SQRF model overestimated, on average, $12 \%$ of the observational data. Also, we noticed that local noon amplitude could be a threshold of the dawn and the dusk amplitudes in the Sq-H field, in which lower value during local noon may delay dawn hours and advance the dusk hours.

The SQRF model seems to have good potential to investigate future data. This fact is of great scientific interest since the prediction analyses would help understand the space climate and the near-Earth environment. Here, we show that the SQRF model algorithm provided predictions with a high confidence level. Finally, the SQRF model successfully describes the Sq-H field in the SAMA region, having the potential to be used for space weather applications since the SAMA is continuously changing through the years.

\section{Conclusions}

The SQRF is an empirical model of the horizontal field daily variation obtained from Embrace MagNet's magnetic field data of 12 magnetic stations between 2010 and 2018. We used this model to get the quiet daily variation of the South American sector's geomagnetic field.

In this work, we evaluated the SQRF accuracy in estimating and predicting the $\mathrm{Sq}-\mathrm{H}$ field over the SAMA. We conducted a careful analysis of the $\mathrm{Sq}-\mathrm{H}$ field data and compared the results with the model's predictions. In general, the results showed that the model output is in good agreement with the observations using groundbased measurements.

Since the model presented accurate data for the sites used to obtain its coefficients, we proposed a spatial interpolation of the modeled parameters to estimate the $\mathrm{Sq}-\mathrm{H}$ field for regions with no measurements. As a case study, the SQRF computed for CBA and SMS was used to obtain the MED station's parameters, a site close to the SAMA center. The selected three locations are at almost the same meridian. We compared the estimated $\mathrm{Sq}-\mathrm{H}$ field for the MED station with the observational data collected in 2018. In general, the results showed a very similar behavior between predictions and observational data. The best correlation was observed in November $(r=0.99)$, and the worst in August $(r=0.94)$.

We also analyzed the accuracy for predicting the Sq-H field over CXP compared with the quiet daily variation field data in 2019. In this case, CXP is part of the dataset used to construct the SQRF model, and the prediction accuracy was tested using data outside the time interval used to build the model. This analysis showed that the SQRF model could predict the daily variation field with high accuracy and a correlation coefficient around 0.98 . The predictions also presented lower RMSE 1 to 2 months ahead. Some improvements would be necessary to reduce the discrepancies that may be associated with the atmospheric tidal winds variability.

This work showed that the SQRF model output could estimate and predict the regular solar quiet daily variation of the geomagnetic field considering the solar cycle dependence and the seasonal and daily variations. In these cases, this model is useful when observational data are absent, and the Sq field is necessary. In this context, the SQRF model might improve the space weather centers' scientific insight and capability to predict the regular solar quiet field variation during geomagnetically quiet conditions. Finally, we believe that the SQRF model is a potential tool for space weather applications.

\section{Acknowledgments}

S.S. Chen thanks CNPq/MCTI (Grant 134151/2017-8) and CAPES/MEC (Grant 88887.362982/2019-00). C.M. Denardini thanks CNPq/MCTI (Grant 303643/2017-0). L.C.A. Resende and J. Moro thank China-Brazil Joint Laboratory for Space Weather (CBJLSW), National Space Science Center (NSSC), and Chinese Academy of Sciences (CAS) for supporting their Postdoctoral fellowship. J. Moro also thanks CNPq/MCTI (Grant 429517/2018-01). R.P. Silva thanks CNPq/MCTI (Grant 300986/2020-3). C.S. Carmo thanks CNPq/MCTI (Grant 141935/2020-0). G.A.S. Picanço thanks CAPES/MEC (Grant 88887.467444/201900). The authors thank the Embrace/INPE for providing the magnetic field data, the GFZ Potsdam for the classification of International Quiet Days, and the Natural Resources Canada (NRC) for providing the monthly average solar radio flux data.

\section{Authors' contributions}

SSC conceived the empirical model, developed the model's computational codes, designed the data analysis, and led writing this manuscript. CMD assisted in conceiving the empirical model and designed the data analysis. LCAR assisted in conceiving the empirical model and designed the data analysis. RAJC assisted in conceiving the empirical model and designed the data analysis. JM assisted in reviewing the manuscript and discussing the results of the study. RPS assisted in reviewing the manuscript and discussing the results of the study. CSC assisted computational codes for designing the figures. GASP assisted in reviewing the manuscript and discussing the results of the study. All the authors helped to write and revise the manuscript. All authors read and approved the final manuscript.

\section{Funding}

This study was financed in part by the Coordenação de Aperfeiçoamento de Pessoal de Nível Superior_-Brasil (CAPES)_Finance Code 001.

\section{Availability of data and materials}

The empirical model of the $\mathrm{Sq}-\mathrm{H}$ field is not available online and the run of predictions will be provided under request to the author. The Embrace/INPE provided the magnetic field data and are available online (http://www.inpe. 
br/spaceweather/). The GeoForschungsZentrum (GFZ) Potsdam provided the list of International Quiet Days and is available online (ftp://ftp.gfz-potsd am.de/pub/home/obs/kp-ap/quietdst/). The Natural Resources Canada (NRC) provided the monthly average of solar radio flux data and are available online (https://www.spaceweather.gc.ca/solarflux/sx-5-en.php). The NOAA National Centers for Environmental Information (NCEI) provided the total field intensity and the magnetic equator from IGRF-13 and are available online (https:// www.ngdc.noaa.gov/geomag/calculators/magcalc.shtml\#igrfgrid). The British Geological Survey (BGS) provided the geomagnetic coordinate calculator and is available online (http://www.geomag.bgs.ac.uk/data_service/model s_compass/coord_calc.html).

\section{Competing interests}

The authors declare that they have no competing interests.

\section{Author details}

${ }^{1}$ National Institute for Space Research (INPE), São José dos Campos, SP, Brazil. ${ }^{2}$ State Key Laboratory of Space Weather, NSSC/CAS, Beijing, China. ${ }^{3}$ Southern Space Coordination (COESU/INPE/MCTI), Santa Maria, RS, Brazil.

\section{Appendix}

Coefficients and phase angles defined in Eqs. (3), (4), and (5) for CBA and SMS are given in Tables 5, 6, 7, respectively.
Table 5 Coefficients of solar cycle parameter

\begin{tabular}{lll}
\hline Station & $\boldsymbol{C}_{\boldsymbol{0}}$ (nT) & $\boldsymbol{C}_{\boldsymbol{1}}$ (nT/sfu) \\
\hline CBA & 27.04 & 0.32 \\
SMS & 6.96 & 0.26 \\
\hline
\end{tabular}

Table 6 Coefficients and phase angles of the seasonality parameter

\begin{tabular}{lllr}
\hline Station & $\boldsymbol{j}$ & $\boldsymbol{S}_{\boldsymbol{j}}(\mathrm{nT})$ & $\boldsymbol{\varphi}_{\boldsymbol{j}}(\mathrm{rad})$ \\
\hline CBA & 0 & 84.91 & \\
& 1 & 3.39 & 2.1933 \\
& 2 & 9.96 & -2.5773 \\
& 3 & 0.29 & 2.8454 \\
& 4 & 2.24 & 1.3937 \\
& 5 & 1.25 & 0.3308 \\
SMS & 6 & 1.06 & 0.0000 \\
& 0 & 46.52 & \\
& 1 & 5.13 & 0.7984 \\
& 2 & 6.36 & -2.1737 \\
& 3 & 1.98 & 1.3867 \\
& 4 & 1.10 & 2.0528 \\
& 5 & 2.72 & 1.1899 \\
& 6 & 0.24 & 0.0000 \\
\hline
\end{tabular}


Table 7 Coefficients and phase angles of the daily parameter

\begin{tabular}{|c|c|c|c|c|c|c|c|c|c|c|}
\hline \multirow[t]{2}{*}{ Station } & \multirow[t]{2}{*}{$m$} & \multicolumn{5}{|c|}{$D_{m, n}(\mathrm{nT})$} & \multicolumn{4}{|c|}{$\varphi_{m, n}(\mathrm{rad})$} \\
\hline & & $n=0$ & $n=1$ & $n=2$ & $n=3$ & $n=4$ & $n=1$ & $n=2$ & $n=3$ & $n=4$ \\
\hline \multirow[t]{12}{*}{ CBA } & 1 & 25.32 & 23.86 & 8.37 & 2.54 & 0.72 & 2.1063 & -2.1558 & 0.5725 & 2.5363 \\
\hline & 2 & 24.12 & 23.97 & 9.57 & 3.88 & 1.33 & 2.1068 & -2.0846 & 0.5210 & -3.1238 \\
\hline & 3 & 29.20 & 27.61 & 12.64 & 7.38 & 1.98 & 2.1415 & -1.8238 & 0.6565 & 3.1343 \\
\hline & 4 & 25.62 & 24.45 & 11.91 & 7.54 & 2.30 & 2.2540 & -1.6331 & 0.7865 & 2.8667 \\
\hline & 5 & 21.42 & 21.01 & 11.15 & 7.16 & 1.95 & 2.3530 & -1.4675 & 0.8492 & 2.6827 \\
\hline & 6 & 19.96 & 20.96 & 11.15 & 6.05 & 1.60 & 2.3695 & -1.5300 & 0.8460 & 2.6151 \\
\hline & 7 & 20.76 & 20.55 & 10.53 & 6.48 & 1.95 & 2.2910 & -1.6025 & 0.7483 & 2.3997 \\
\hline & 8 & 23.52 & 23.73 & 12.69 & 7.45 & 1.80 & 2.2454 & -1.6966 & 0.6220 & 2.5694 \\
\hline & 9 & 27.80 & 28.13 & 14.71 & 9.15 & 2.67 & 2.2764 & -1.6627 & 0.7546 & 2.7935 \\
\hline & 10 & 30.05 & 29.82 & 12.78 & 7.19 & 2.58 & 2.1312 & -1.7936 & 1.0084 & -2.6353 \\
\hline & 11 & 26.44 & 26.76 & 10.87 & 4.42 & 0.87 & 2.2210 & -1.6910 & 1.0463 & -2.5885 \\
\hline & 12 & 23.82 & 23.20 & 8.59 & 2.88 & 0.27 & 2.1603 & -1.9505 & 0.9166 & 2.7963 \\
\hline \multirow[t]{12}{*}{ SMS } & 1 & 19.10 & 17.10 & 4.58 & 0.79 & 0.94 & 2.3583 & -2.1424 & -1.0001 & 0.9992 \\
\hline & 2 & 15.03 & 16.09 & 6.94 & 2.02 & 0.92 & 2.4085 & -2.0921 & -0.0845 & 2.3666 \\
\hline & 3 & 17.21 & 16.27 & 7.12 & 3.03 & 1.30 & 2.3232 & -1.9994 & 0.1858 & 1.6815 \\
\hline & 4 & 15.02 & 14.97 & 6.64 & 3.49 & 1.71 & 2.6553 & -1.4531 & 0.6102 & 1.9698 \\
\hline & 5 & 9.30 & 9.46 & 5.06 & 3.39 & 1.48 & 2.8168 & -0.7028 & 1.3859 & 2.4201 \\
\hline & 6 & 9.29 & 9.75 & 4.54 & 2.86 & 1.30 & 2.8266 & -0.8110 & 1.4376 & 2.5925 \\
\hline & 7 & 11.25 & 9.89 & 3.94 & 2.91 & 1.19 & 2.6283 & -0.9581 & 1.3203 & 2.1527 \\
\hline & 8 & 14.35 & 14.13 & 6.67 & 3.85 & 1.77 & 2.6597 & -1.2616 & 0.8058 & 2.1330 \\
\hline & 9 & 17.48 & 18.62 & 8.45 & 3.96 & 1.83 & 2.6074 & -1.4914 & 0.7222 & 2.0236 \\
\hline & 10 & 16.93 & 16.67 & 5.75 & 1.78 & 1.16 & 2.4223 & -1.7852 & 0.6922 & 2.2022 \\
\hline & 11 & 17.05 & 17.86 & 6.42 & 1.51 & 1.17 & 2.4628 & -1.7402 & 0.3131 & 1.9680 \\
\hline & 12 & 15.88 & 16.11 & 5.67 & 1.37 & 1.27 & 2.4747 & -1.9115 & -0.5914 & 1.3125 \\
\hline
\end{tabular}

Received: 8 Auqust 2020 Accepted: 17 February 2021

Published online: 03 March 2021

\section{References}

Abdu MA, Batista IS (1977) Sporadic E-layer phenomena in the Brazilian geomagnetic anomaly: evidence for a regular particle ionization source. J Atmos Terr Phys 39(6):723-732. https://doi.org/10.1016/00219169(77)90059-9

Anderson PC, Rich F, Borisov S (2018) Mapping the South Atlantic Anomaly continuously over 27 years. J Atmos Solar Terr Phys 177:237-246. https:// doi.org/10.1016/j.jastp.2018.03.015

Bala R, Reiff P (2018) data availability and forecast products for space weather. In: Camporeale E, Wing S, Johnson JR (eds) Machine learning techniques for space weather. Elsevier, Amsterdam, pp 27-41. https://doi. org/10.1016/B978-0-12-811788-0.00002-0

Batista PP, Clemesha BR, Tokumoto AS, Lima LM (2004) Structure of the mean winds and tides in the meteor region over Cachoeira Paulista, Brazil $\left(22.7^{\circ} \mathrm{S}, 45^{\circ} \mathrm{W}\right)$ and its comparison with models. J Atmos Solar Terrestrial Phys 66(6):623-636. https://doi.org/10.1016/j.jastp.2004.01.014

Bolzan MJA, Denardini CM, Tardelli A (2018) Comparison of H component geomagnetic field time series obtained at different sites over South America. Ann Geophys 36:937-943. https://doi.org/10.5194/angeo-36-937-2018

Campbell WH (1989) An introduction to quiet daily geomagnetic fields. Pure Appl Geophys 131:315-331. https://doi.org/10.1007/BF00876831

Campbell WH, Schiffmacher ER, Kroehl HW (1989) Global quiet day field variation model WDCA/SQ1. Eos Trans Am Geophys Union 70(5):66-74. https ://doi.org/10.1029/89eo00039
Chen SS, Denardini CM, Resende LCA, Chagas RAJ, Moro J, Picanço GAS (2020) Development of an empirical model for estimating the Quiet Day Curve (QDC) over the Brazilian sector. Radio Sci. https://doi.org/10.1029/2020R S007105

Chulliat A, Vigneron P, Hulot G (2016) First results from the Swarm Dedicated Ionospheric Field Inversion chain. Earth Planets Space. https://doi. org/10.1186/s40623-016-0481-6

Chulliat A, Brown W, Alken P, Beggan C, Nair M, Cox G, Woods A, Macmillan S, Meyer B, Paniccia M (2020) The US/UK World Magnetic Model for 20202025: Technical Report, National Centers for Environmental Information, NOAA. https://doi.org/10.25923/ytk1-yx35.

Davila JM, Poland Al, Harrison RA (2004) International Heliophysical Year: a program of global research continuing the tradition of previous international years. Adv Space Res 34(11):2453-2458. https://doi.org/10.1016/j. asr.2004.07.008

Denardini CM, Silva MRD, Gende MA, Chen SS, Fagundes PR, Schuch NJ, Petry A, Resende LCA, Moro J, Padilha AL, Sant'Anna N, Alves L (2015) The initial steps for developing the South American K index from the Embrace magnetometer network. Braz Geophys J 33(1):79-88. https://doi.org/10.22564 /rbgf.v33i1.603

Denardini CM, Dasso S, Gonzalez-Esparza JA (2016) Review on space weather in Latin America. 3. Development of space weather forecasting centers. Adv Space Res 58(10):1960-1967. https://doi.org/10.1016/j. asr.2016.03.011

Denardini CM, Chen SS, Resende LCA, Moro J, Bilibio AV, Fagundes PR, Gende MA, Cabrera MA, Bolzan MJA, Padilha AL, Schuch NJ, Hormaechea JL, Alves LR, Neto PFB, Nogueira PAB, Picanço GAS, Bertollotto TO (2018a) The Embrace magnetometer network for South America: network description and its qualification. Radio Sci 53(3):288-302. https://doi. org/10.1002/2017RS006477 
Denardini CM, Chen SS, Resende LCA, Moro J, Bilibio AV, Fagundes PR, Gende MA, Cabrera MA, Bolzan MJA, Padilha AL, Schuch NJ, Hormaechea JL, Alves LR, Neto PFB, Nogueira PAB, Picanço GAS, Bertollotto TO (2018b) The Embrace magnetometer network for South America: first scientific results. Radio Science 53(3):379-393. https://doi.org/10.1002/2018RS0065 40

Denardini CM, Picanço GAS, Barbosa Neto PF, Nogueira PAB, Carmo CS, Resende LCA, Moro J, Chen SS, Romero-Hernandez E, Silva RP, Bilibio AV (2020) lonospheric scale index map based on TEC data for space weather studies and applications. Space Weather. https://doi.org/10.1029/2019S W002328

Espinosa KV, Padilha AL, Alves LR (2019) Effects of ionospheric conductivity and ground conductance on geomagnetically induced currents during geomagnetic storms: Case studies at low-latitude and equatorial regions. Space Weather 17:252-268. https://doi.org/10.1029/2018SW002094

Finlay CC, Kloss C, Olsen N, Hammer MD, Tøffner-Clausen L, Grayver A, Kuvshinov A (2020) The CHAOS-7 geomagnetic field model and observed changes in the South Atlantic Anomaly. Earth Planets Space. https://doi. org/10.1186/s40623-020-01252-9

Forbes JM, Zhang X, Palo S, Russell J, Mertens CJ, Mlynczak M (2008) Tidal variability in the ionospheric dynamo region. J Geophys Res 113:A02310. https://doi.org/10.1029/2007JA012737

Hartmann GA, Pacca IG (2009) Time evolution of the South Atlantic Magnetic Anomaly. Ann Braz Acad Sci 81(2):243-255. https://doi.org/10.1590/ S0001-37652009000200010

Jankowski J, Sucksdorff C (1996) IAGA guide for magnetic measurements and observatory practice. IAGA, Warsaw

Janzhura AS, Troshichev OA (2008) Determination of the running quiet daily geomagnetic variation. J Atmos Solar Terr Phys 70(7):962-972. https://doi. org/10.1016/j.jastp.2007.11.004

Kane RP (1976) Geomagnetic field variations. Space Sci Rev 18(4):413-540. https://doi.org/10.1007/BF00217344

Klausner V, Domingues MO, Mendes O Jr, da Costa AM, Papa ARR, Gonzalez AO (2016) Latitudinal and longitudinal behavior of the geomagnetic field during a disturbed period: A case study using wavelet techniques. Adv Space Res 58(10):2148-2163. https://doi.org/10.1016/j.asr.2016.01.018

Love JJ (2008) Magnetic monitoring of Earth and space. Phys Today 61(2):3137. https://doi.org/10.1063/1.2883907

Love JJ, Finn CA (2017) Real-time geomagnetic monitoring for space weatherrelated applications: Opportunities and challenges. Space Weather 15:820-827. https://doi.org/10.1002/20175W001665

Mandea M, Chambodut A (2020) Geomagnetic field processes and their implications for space weather. Surv Geophys 41:1611-1627. https://doi. org/10.1007/s10712-020-09598-1

Moro J, Denardini CM, Resende LCA, Chen SS, Schuch NJ (2016) Equatorial $\mathrm{E}$ region electric fields at the dip equator: 2 . Seasonal variabilities and effects over Brazil due to the secular variation of the magnetic equator. J Geophys Res Space Phys 121(10):10231-10240. https://doi. org/10.1002/2016JA022753

Pinto O Jr, Gonzalez WD, Pinto IRCA, Gonzalez ALC, Mendes O Jr (1992) The South Atlantic Magnetic Anomaly: three decades of research. J Atmos Terr Phys 54(9):1129-1134. https://doi.org/10.1016/0021-9169(92)90137-A

Rastogi RC, Alex S, Patil A (1994) Seasonal variations of geomagnetic D, H and Z fields at low latitudes. J Geomagn Geoelectr 46(2):115-126. https://doi. org/10.5636/jgg.46.115

Resende LCA, Batista IS, Denardini CM, Batista PP, Carrasco AJ, Andrioli VF, Moro $J$ (2017) Simulations of blanketing sporadic E-layer over the Brazilian sector driven by tidal winds. J Atmos Solar Terr Phys 154:104-114. https://doi. org/10.1016/j.jastp.2016.12.012

Resende LCA, Denardini CM, Picanço GAS, Moro J, Barros D, Figueiredo CAOB, Silva RP (2019) On developing a new ionospheric plasma index for Brazilian equatorial F region irregularities. Ann Geophys 37:807-818. https:// doi.org/10.5194/angeo-37-807-2019

Richmond AD (1979) lonospheric Wind Dynamo Theory: A Review. J Geomagn Geoelectr 31(3):287-310. https://doi.org/10.5636/jgg.31.287

Rodger CJ, Clilverd MA, Mac Manus DH, Martin I, Dalzell M, Brundell JB, Divett T, Thomson NR, Petersen T, Obana Y, Watson NR (2020) Geomagnetically induced currents and harmonic distortion: storm-time observations from New Zealand. Space Weather. https://doi.org/10.1029/2019SW002387

Sabaka TJ, Tøffner-Clausen L, Olsen N, Finlay C (2020) CM6: a comprehensive geomagnetic field model derived from both CHAMP and Swarm satellite observations. Earth Planets Space. https://doi.org/10.1186/s40623-02001210-5

Schrijver CJ, Kauristie K, Aylward AD, Denardini CM, Gibson SE, Glover A, Gopalswamy N, Grande M, Hapgood M, Heynderickx D, Jakowski N, Kalegaev VV, Lapenta G, Linker JA, Liu S, Mandrini CH, Mann IR, Nagatsuma T, Nandy D, Obara T, O'Brien TP, Onsager T, Opgenoorth HJ, Terkildsen M, Valladares CE, Vilmer N (2015) Understanding space weather to shield society: a global road map for 2015-2025, commissioned by COSPAR and ILWS. Adv Space Res 55(12):2745-2807. https://doi.org/10.1016/j. asr.2015.03.023

Shinbori A, Koyama Y, Nosé M, Hori T, Otsuka Y (2017) Characteristics of seasonal variation and solar activity dependence of the geomagnetic solar quiet daily variation. J Geophys Res Space Phys 122(10):10796-10810. https://doi.org/10.1002/2017JA024342

Soares G, Yamazaki Y, Cnossen I, Matzka J, Pinheiro KJ, Morschhauser A, Alken P, Stolle C (2020) Evolution of the geomagnetic daily variation at Tatuoca, Brazil, from 1957 to 2019: a transition from Sq to EEJ. J Geophys Res Space Phys. https://doi.org/10.1029/2020JA028109

Stauning P (2011) Determination of the quiet daily geomagnetic variations for polar regions. J Atmos Solar Terr Phys 73(16):2314-2330. https://doi. org/10.1016/j.jastp.2011.07.004

Sutcliffe PR (1999) The development of a regional geomagnetic daily variation model using neural networks. Ann Geophys 18(1):120-128. https://doi. org/10.1007/s00585-000-0120-0

Thébault E, Finlay CC, Beggan CD, Alken P, Aubert J, Barrois O, Bertrand F, Bondar T, Boness A, Brocco L, Canet E, Chambodut A, Chulliat A, Coïsson P, Civet F, Du A, Fournier A, Fratter I, Gillet N, Hamilton B, Hamoudi M, Hulot G, Jager T, Korte M, Kuang W, Lalanne X, Langlais B, Léger J-M, Lesur V, Lowes FJ, Macmillan S, Mandea M, Manoj C, Maus S, Olsen N, Petrov V, Ridley V, Rother M, Sabaka TJ, Saturnino D, Schachtschneider R, Sirol O, Tangborn A, Thomson A, Tøffner-Clausen L, Vigneron P, Wardinski I, Zvereva T (2015) International Geomagnetic Reference Field: the 12th generation. Earth Planets Space. https://doi.org/10.1186/s4062 3-015-0228-9

Thomson AWP (2014) Geomagnetic observatories: monitoring the Earth's magnetic and space weather environment. Weather 69(9):234-237. https ://doi.org/10.1002/wea.2329

Unnikrishnan K (2014) Prediction of horizontal component of Earth's magnetic field over Indian sector using neural network model. J Atmos Solar Terr Phys 121:206-220. https://doi.org/10.1016/j.jastp.2014.06.014

Van de Kamp M (2013) Harmonic quiet-day curves as magnetometer baselines for ionospheric current analyses. Geosci Instrum Methods Data Syst 2(2):289-304. https://doi.org/10.5194/gi-2-289-2013

Yamazaki Y, Maute A (2017) Sq and EEJ_a review on the daily variation of the geomagnetic field caused by ionospheric dynamo currents. Space Sci Rev 206:299-405. https://doi.org/10.1007/s11214-016-0282-z

Yamazaki Y, Yumoto K, Cardinal MG, Fraser BJ, Hattori P, Kakinami Y, Liu JY, Lynn KJW, Marshall R, Mcnamara D, Nagatsuma T, Nikiforov VM, Otadoy RE, Ruhimat M, Shevtsov BM, Shiokawa K, Abe S, Uozumi T, Yoshikawa A (2011) An empirical model of the quiet daily geomagnetic field variation. J Geophys Res Space Phys 116(A10312):1-21. https://doi. org/10.1029/2011JA016487

Yamazaki Y, Richmond AD, Maute A, Wu Q, Ortland DA, Yoshikawa A, Adimula IA, Rabiu B, Kunitake M, Tsugawa T (2014) Ground magnetic effects of the equatorial electrojet simulated by the TIE-GCM driven by TIMED satellite data. J Geophys Res Space Phys 119(4):3150-3161. https://doi. org/10.1002/2013JA019487

Yamazaki Y, Häeusler K, Wild JA (2016) Day-to-day variability of midlatitude ionospheric currents due to magnetospheric and lower atmospheric forcing. J Geophys Res Space Phys 121(7):7067-7086. https://doi. org/10.1002/2016JA022817

Yumoto K, the $210^{\circ} \mathrm{MM}$ Magnetic Observation Group (1996) The STEP $210^{\circ}$ magnetic meridian network project. J Geomagn Geoelectr 48(11):12971309. https://doi.org/10.5636/jgg.48.1297

\section{Publisher's Note}

Springer Nature remains neutral with regard to jurisdictional claims in published maps and institutional affiliations. 